\title{
Effects of Self-Presentation on One's Self-Regulatory Resources When One Is Faced with the Multiple Audience Problem
}

\author{
Yu Kasagi ${ }^{1}$, Ikuo Daibo² \\ ${ }^{1}$ Faculty of Psychology, Rissho University, Tokyo, Japan \\ ${ }^{2}$ School of Motivation \& Behavioral Sciences, Tokyo Future University, Tokyo, Japan \\ Email: yuukasagi@ris.ac.jp
}

Received 31 July 2015; accepted 2 September 2015; published 7 September 2015

Copyright (c) 2015 by authors and Scientific Research Publishing Inc.

This work is licensed under the Creative Commons Attribution International License (CC BY). http://creativecommons.org/licenses/by/4.0/

(c) $\underset{\mathrm{EY}}{\mathrm{E}} \mathrm{i}$

\section{Abstract}

This study examined the effects of self-presentation on participants' self-regulatory resources when the participants were faced with the multiple audience problem. In the experiment, participants $(N=38)$ were assigned to either the consistent condition or inconsistent condition, and were asked to make a speech in three sessions. The inconsistent condition was manipulated such that the participants would be confronted with the multiple audience problem in speech session 3 . After the three speech sessions, the participants were told to work on 200 multiplication problems ( 3 digits $\times 3$ digits) until they had finished solving all the problems or until they gave up or felt that they were unable to continue working on the problems. An experimenter timed the participants with a stopwatch as they worked on the problems. The results showed that the participants in the inconsistent condition gave up faster than the participants in the consistent condition. Moreover, the participants in the inconsistent condition solved less multiplication problems than the participants in the consistent condition. On the basis of these results, we concluded that when one was faced with the multiple audience problem, self-presentation was extremely difficult and entailed effortful forms of self-presentation that depleted one's self-regulatory resources. Further research is necessary to examine the effects of compensatory self-enhancement, which has been found to be an effective coping strategy on self-regulatory resources when one is faced with the multiple audience problem.

\section{Keywords}

Self-Presentation, Self-Regulatory Resources, Multiple Audience Problem 


\section{Introduction}

Presenting oneself effectively to others results in one making friends and also in occupational success, psychological well-being, and other desirable outcomes (Leary, 1995; Rosenfeld, Giacalone, \& Riordan, 2002; Schlenker, 2003). Consequently, people often monitor and attempt to control the impressions they are making, and it's a process known as self-presentation or impression management (Goffman, 1959; Leary \& Allen, 2011).

It has been shown that people manage the impression they are making depending on the social context and their relationship partners present in that situation (Swann, Bosson, \& Pelham, 2002). For instance, people pay more attention to enhancing their appearance for opposite-sex others than for same-sex others (Leary, Nezlek, Downs, Radford-Davenport, Martin, \& McMullen, 1994). Hence, people are often at a loss about how to behave in a situation where their behaviors are simultaneously being witnessed by several sets of individuals to whom they wish to presentdifferent personalities. An example of such a situation would be a female college student who is talking to her boyfriend in the classroom and who is also aware that her same-sex friends are listening to the conversation. These difficult self-presentation dilemmas in which a person is faced with two or more "audiences" while simultaneously wanting each audience to form or maintain a different impression of him/her is referred to as the multiple audience problem (Fleming, 1994; Fleming, Darley, Hilton, \& Kojetin, 1990). In life, people are often confronted with this problem (Kasagi \& Daibo, 2013; Nichols \& Cottrell, 2008) and have difficulty in presenting themselves in such situations, ultimately being unable to present themselves effectively (e.g., Fleming et al., 1990; Van Boven, Kruger, Savitsky, \& Gilovich, 2000). However, the mechanism responsible for people failing to effectively engage in self-presentation in a multiple audience context remains to be delineated. The failure of self-presentation due to the multiple audience problem decreases the presenter's self-esteem and a negative impression of the presenter is conveyed (Kasagi \& Daibo, under review). Thus, it is important to determine and elucidate the mechanism due to which people fail to effectively self-present in a multiple audience context.

Recently, self-regulatory resource depletion has been focused on as the explanation for the failure to effectively engage in self-presentation (Vohs, Baumeister, \& Ciarocco, 2005). Self-regulation depends on limited resources, akin to energy or strength (Baumeister \& Heatherton, 1996; Heatherton \& Baumeister, 1996). The same resources are used for widely different self-regulatory tasks, including the regulation of cognition and thought, of emotion, of impulsive and appetitive behaviors, and of performances (e.g., Baumeister, Bratslavsky, Finkenauer, \& Vohs, 2001; Muraven, Tice, \& Baumeister, 1998; Vohs \& Baumeister, 2004). Accordingly, if a person attempts to engage in several demanding self-regulatory tasks simultaneously or consecutively, the chance of success at any one of them is significantly reduced.

Most treatments of the self-regulatory resource model involve the use of a two-task design to test for the effect of performing one self-regulatory task on the performance of another subsequent task. First, participants perform either a target task designed to consume regulatory resources (e.g., resisting temptation, regulating thoughts) or a control task thought to consume few or no regulatory resources. Next, all the participants perform a second regulatory task, which represents the dependent measure (e.g., persistence on an unsolvable puzzle; see Vohs \& Heatherton, 2000). Resource depletion is said to have occurred when people who performed the first task perform worse on the second task than the case of people who did not engage in self-regulation in the first task.

Because people have to use effortful and deliberate control over their behavior to select and convey the appropriate image, self-presentation behavior consumes their self-regulatory resources (Leary \& Kowalski, 1990). Vohs et al. (2005) used a two-task design to investigate the relationship between self-regulatory resources and self-presentation. In their experiment, the participants were randomly assigned to either the habitual self-presentation condition or the unfamiliar self-presentation condition. After the self-presentation session, the participants were told to work on multiplication problems as a self-regulatory task. As a result, the participants who presented themselves using unfamiliar and effortful forms of self-presentation gave up faster than the participants who presented themselves in a standard, familiar, or habitual manner or who engaged in only minimal self-presentation.

Most interpersonal behavior involves communicating information about oneself or presenting an image of oneself to others (Baumeister, 1982; Schlenker, 1980). For instance, Leary et al. (1994) reported that people spent more than three hours every day, consciously shaping and manipulating their public images. Therefore, it is not surprising that people develop standard, familiar ways of presenting themselves to others. Generally, 
people present fairly uniform versions of themselves, versions that consist of some degree of truth and some degree of editing, to depict a favorable, socially desirable image (e.g., Leary \& Kowalski, 1990; Schlenker, 1975, 1980; Tesser \& Moore, 1986). They also learn to conform to specific rules about how to be viewed favorably by others (e.g., Leary et al., 1994; Tice, Butler, Muraven, \& Stillwell, 1995). As self-presentations become more practiced and habitual, they also become more efficient, require less effort, and eventually become automatized. Bargh (1994) theorized that processes that were frequently engaged in become automatized, a transformation that resulted in greater efficiency. Indeed, Vallacher \& Wegner (1987) showed that when people's usual routines were disrupted or when people found themselves in an unfamiliar situation, they were pulled out of an inattentive, mindless state and must exert increased attentional and behavioral control to enact the desired response successfully.

Hence, situations where people have to present themselves in a non-standard, unfamiliar style require more self-regulation, because these acts involve overriding familiar responses and actively controlling one's behavior. When choosing strategic behaviors, people may use volition and self-regulation in selecting the image they want to present (Leary \& Kowalski, 1990). When a person engages in these more effortful forms of self-presentation, more self-regulatory resources are drained than when people present themselves in a standard, familiar, or habitual manner or when they engage in only minimal self-presentation (Vohs et al., 2005). Self-presentation is difficult when a person is faced with the multiple audience problem and in non-standard self-presentation situations. Thus, it is evident that self-presentation in the multiple audience context requires more effortful self-regulation and consumes more self-regulatory resources.

The current study examined the effects of participants' self-presentation on their self-regulatory resources when they were faced with the multiple audience problem. In this study, the experimental situation involving the multiple audience problem was created by manipulating the content of a speech (see Van Boven et al., 2000). The self-regulatory task consisted of 3-digit $\times 3$-digit multiplication problems (Vohs \& Heatherton, 2000). Vohs \& Schmeichel (2003) showed that this multiplication task was rather tedious and the desire to stop arose quickly; hence, one required persistence to override the urge to quit and one needed exert extra effort to continue. We predicted that self-presentation in the multiple audience context would require more self-regulatory resources than in a context having just one audience member. We assumed that the participants in such multiple audience problem conditions would therefore experience self-regulatory resource depletion by the end of the speech session. They would presumably have fewer resources to help them continue working on the multiplication problems, and as a result, we predicted that they would give up faster than the participants in the other conditions.

\section{Method}

\subsection{Participants}

Thirty-eight female college students (average age 20.2 years old, standard deviation 1.79) participated in the study. Moroi (1987) showed that women's self-monitoring scores higher than men's one, and Kasagi \& Daibo (2013) suggested that high self-monitor frequently faced with the multiple audience problem. Therefore, this study treated only female participants.

\subsection{Procedure}

The participants were invited to the laboratory individually for this study, which they were told attended speech communication experiment, and they were randomly assigned to either the inconsistent condition $(N=19, M=$ $20.3, S D=2.16)$ or consistent condition $(N=19, M=20.2, S D=1.38)$. The participants were informed that the study would consist of three brief sessions. Table 1 shows the topics of the speech the participants were asked to make in each session. Because the participants in the inconsistent condition were required to make a contradictory speech in session 1 and session 2, they were faced with the multiple audience problem in session 3 . The speech topics of sessions 1 and 2 were counterbalanced.

Session 1. The participants were shown a speech topic (Table 1). Then, they were asked to make the speech on the topic in front of a video camera. They were also told that same college student, A, would watch their speech video, and evaluate his/her impression of them. Then, the participants rehearsed their speech and made it for two minutes in front of the video camera. While the participants were making their speech, the experimenter left the laboratory. 
Table 1. Participants' speech topics.

\begin{tabular}{ccc}
\hline Consistency of speech & Session 1 & Session 2 \\
\hline Inconsistent & Nerd (or Party animal) & Party animal (or Nerd) \\
Consistent & Nerd (or Party animal) & Nerd (or Party animal) \\
\hline
\end{tabular}

Note. The speech topics of sessions 1 and 2 were counterbalanced.

Session 2. The participants were shown a speech topic (Table 1). Then, they were asked to make the speech in front of the video camera. They were also told that same college student, B, would watch their speech video and evaluate their speech. Then, the participants rehearsed their speech, and made it for two minutes in front of the video camera. While the participants were making their speech, the experimenter left the laboratory.

Session 3. The participants were asked to make a speech in front of the video camera. Then, they were told that both students A and B would watch their speech video and evaluate their speech. It was emphasized that they had to maintain the identities that they had presented in sessions 1 session 2 . Then, the participants rehearsed their speech and made it for two minutes in front of the video camera. While the participants were making their speech, the experimenter left the laboratory.

After session 3, the participants were asked to participate in another experiment. They were presented with 200 3-digit $\times 3$-digit multiplication problems and were asked to work on them until they had finished solving all the problems or until they decided to stop working on them (Vohs \& Heatherton, 2000). After the participants signaled that they had finished solving all the problems or had decided to stop, they were debriefed and thanked.

\section{Results}

The main hypothesis was that persistence on the 3-digit $\times 3$-digit multiplication problems would depend on the depletion of self-regulatory resources during the speeches. It was predicted that the participants in the inconsistent condition, who were consequently confronted with the multiple audience problem, would give up faster on the mathematics problems than the participants in the consistent condition, who did not have to face the multiple audience problem. To test this hypothesis, we conducted a two-sample t-test with audience condition (inconsistent vs. consistent) as the predictor of time spent on solving the multiplication problems (Figure 1). The analysis revealed that the participants in the inconsistent condition gave up on solving the problems faster than did the participants in the consistent condition $(t(36)=5.69, p<.001)$.

To test the hypothesis, we also conducted two-sample t-tests with audience condition (inconsistent vs. consistent) as predictors of the number of problems solved (Figure 2). The analysis revealed that the participants in the inconsistent condition solved less multiplication problems than the participants in the consistent condition $(t$ $(36)=5.22, p<.001)$.

\section{Discussion}

This study examined the effects of participants' self-presentation on their self-regulatory resources when they were faced with the multiple audience problem. The participants were assigned to either the consistent condition or inconsistent condition, and were asked to make speeches in three sessions. After this, they were told to work on 200 3-digit $\times$ 3-digit multiplication problems until they had finished solving all the problems or until they had given up or had decided to stop working. The results supported our prediction that the participants in the inconsistent condition would give up significantly faster than the participants in the consistent condition. Furthermore, the participants in the inconsistent condition solved significantly less multiplication problems than the participants in the consistent condition. The participants in the inconsistent condition were required to make a contradictory speech in session 1 and session 2; therefore, they were confronted with the multiple audience problem in session 3. On the one hand, the participants in the consistent condition made the same speech in sessions 1,2 , and 3. Vohs et al. (2005) indicated that when people engage in more effortful forms of self-presentation, more self-regulatory resources are drained than when they present themselves in a standard, familiar, or habitual manner or when they engage in only minimal self-presentation. Therefore, it is considered that when one is faced with the multiple audience problem, self-presentation is extremely difficult and entails effortful forms of self-presentation that deplete one's self-regulatory resources. From the results of this study, we understand the mechanism due to which people fail to effectively self-present in a multiple audience context. 


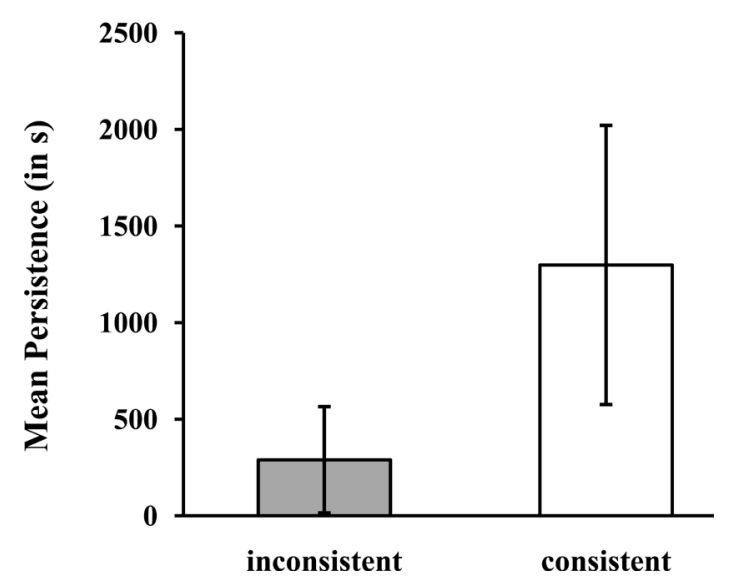

Figure 1. Mean persistence as a function of condition; mean persistence = the amount of time participants spent on a lengthy mathematical task.

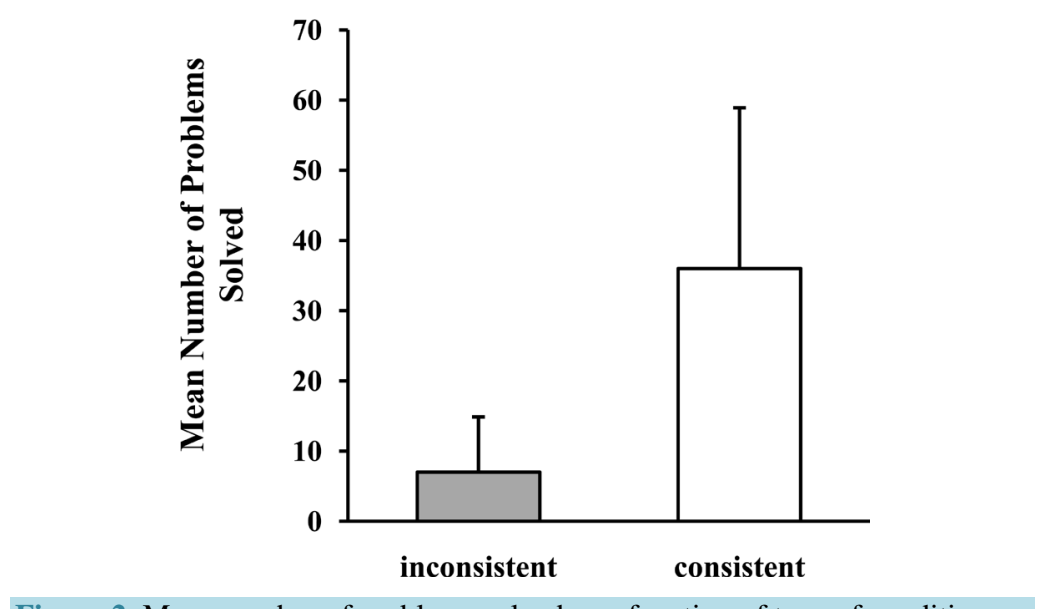

Figure 2. Mean number of problems solved as a function of type of condition.

Kasagi \& Daibo (under review) examined compensatory self-enhancement as a coping strategy for the multiple audience problem. Their study revealed that when a presenter engaged in compensatory self-enhancement (Baumeister \& Jones, 1978) when he/she was faced with the multiple audience problem, it was effective in preventing a decrease in the presenter's self-esteem and in preventing a negative impression of the presenter being conveyed. Moreover, when self-regulatory resources had been depleted by prior acts of self-control, self-presentation drifted toward less-effective patterns of self-presentation (Vohs et al., 2005). Thus, future research should examine the effects of compensatory self-enhancement on self-regulatory resources when people are faced with the multiple audience problem.

Most studies about self-regulation have investigated the intrapsychic processes, but there have been few studies focusing the interpersonal processes (e.g., Baumeister, Heatherton, \& Tice, 1994; Carver \& Scheier, 1982; Higgings, 1996). This study confirmed that self-regulatory resources were especially needed for interpersonal processes that demanded emotional, attentional and cognitive control (Vohs et al., 2005). Also the present study demonstrated that self-presentation was an important dimension of interpersonal functioning that might often demand regulatory resources.

Vohs et al. (2005) suggested that participants' mood affected the performance of a subsequent task. In other words, it is possible that participants' failure at self-presentation when faced with the multiple audience problem decreases their motivation for working on multiplication problems. However, this study did not consider the participants' mood at the end of each speech session. Thus, in order to determine the role of mood, further research that involves controlling participants' mood by using the Positive and Negative Affect Schedule (PANAS; Watson, Clark, \& Tellegen, 1988) is needed.

Further, this study targeted only women. Men and women generally emphasize different qualities when pre- 
senting themselves to other people, with men underscoring their accomplishments and competencies, and women highlighting their interpersonal skills and relational qualities (Derlega, Metts, Petronio, \& Margulis, 1993; Leary et al., 1994). Therefore, subsequent studies should include men, so that the differences between men and women with regard to the effects of self-presentation behavior on self-regulatory resources when they are faced with the multiple audience problem can be examined.

\section{Conclusion}

This study examined the effects of self-presentation on participants' self-regulatory resources when the participants were faced with the multiple audience problem. The results show when one is faced with the multiple audience problem, self-presentation is extremely difficult and entails effortful forms of self-presentation that deplete one's self-regulatory resources.

\section{Acknowledgements}

We would like to thank the Psychological Research Institute, Rissho University, for their generous financial assistance in supporting this study.

\section{References}

Bargh, J. A. (1994). The Four Horsemen of Automaticity: Awareness, Intention, Efficiency, and Control in Social Cognition. In R. S. Wyer Jr., \& T. K. Srull (Eds.), Handbook of Social Cognition (pp. 1-40). Hillsdale, NJ: Erlbaum.

Baumeister, R. F. (1982). A Self-Presentational View of Social Phenomena. Psychological Bulletin, 91, 3-26. http://dx.doi.org/10.1037/0033-2909.91.1.3

Baumeister, R. F., \& Heatherton, T. F. (1996). Self-Regulation Failure: An Overview. Psychological Inquiry, 7, 1-15. http://dx.doi.org/10.1207/s15327965pli0701 1

Baumeister, R. F., \& Jones, E. E. (1978). When Self-Presentation Is Constrained by the Target’s Knowledge: Consistency and Compensation. Journal of Personality and Social Psychology, 36, 608-618. http://dx.doi.org/10.1037/0022-3514.36.6.608

Baumeister, R. F., Bratslavsky, E., Finkenauer, C., \& Vohs, K. D. (2001). Bad Is Stronger Than Good. Review of General Psychology, 5, 323-370. http://dx.doi.org/10.1037/1089-2680.5.4.323

Baumeister, R. F., Heatherton, T. F., \& Tice, D. M. (1994). Losing Control: How and Why People Fail at Self-Regulation. San Diego, CA: Academic Press.

Carver, C. S., \& Scheier, M. F. (1982). Control Theory: A Useful Conceptual Framework for Personality—Social, Clinical, and Health Psychology. Psychological Bulletin, 92, 111-135. http://dx.doi.org/10.1037/0033-2909.92.1.111

Derlega, V., Metts, S., Petronio, S., \& Margulis, S. (1993). Self-Disclosure. Newbury Park, CA: Sage Publications.

Fleming, J. H. (1994). Multiple Audience Problems, Tactical Communication, and Social Interaction: A Relational-Regulation Perspective. In M. P. Zanna (Ed), Advances in Experimental Social Psychology (Vol. 26, pp. 215-292). San Diego, CA: Academic Press.

Fleming, J. H., Derley, J. M., Hilton, J. L., \& Kojetin, B. A. (1990). Multiple Audience Problem: A Strategic Communication Perspective on Social Perception. Journal of Personality and Social Psychology, 58, 593-609. http://dx.doi.org/10.1037/0022-3514.58.4.593

Goffman, E. (1959). The Presentation of Self in Everyday Life. Garden City, NY: Doubleday.

Heatherton, T. F., \& Baumeister, R. F. (1996). Self-Regulation Failure: Past, Present, and Future. Psychological Inquiry, 7 , 90-98. http://dx.doi.org/10.1207/s15327965pli0701_20

Higgings, E. T. (1996). The "Self Digest”: Self-Knowledge Serving Self-Regulatory Functions. Journal of Personality and Social Psychology, 71, 1062-1083. http://dx.doi.org/10.1037//0022-3514.71.6.1062

Kasagi, Y., \& Daibo, I. (2013). The Relation between the Confidence of Resolving the Multiple Audience Problem and SelfComplexity. Proceedings of the 54th Japanese Society of Social Psychology Conference, Okinawa, 2-3 November 2013, 428.

Kasagi, Y., \& Daibo, I. (Under Review). The Effects of the Compensatory Self-Presentation in the Multiple Audience Situations on the Intrapersonal and Interpersonal Adaptation.

Leary, M. R. (1995). Self-Presentation: Impression Management and Interpersonal Behavior. Boulder, CO: Westview Press. Leary, M. R., \& Allen, A. B. (2011). Self-Presentational Persona: Simultaneous Management of Multiple Impressions. 
Journal of Personality and Social Psychology, 101, 1033-1049. http://dx.doi.org/10.1037/a0023884

Leary, M. R., \& Kowalski, R. M. (1990). Impression Management: A Literature Review and Two-Component Model. Psychological Bulletin, 107, 34-47. http://dx.doi.org/10.1037//0033-2909.107.1.34

Leary, M., Nezlek, J. B., Downs, D., Radford-Davenport, J., Martin, J., \& McMullen, A. (1994). Self-Presentation in Everyday Interactions: Effects of Target Familiarity and Gender Composition. Journal of Personality and Social Psychology, 67, 664-673. http://dx.doi.org/10.1037/0022-3514.67.4.664

Moroi, K. (1987). Loneliness and Self-Consciousness in University Students. Japanese Journal of Experimental Social Psychology, 26, 151-161. http://dx.doi.org/10.2130/jjesp.26.151

Muraven, M., Tice, D. M., \& Baumeister, R. F. (1998). Self-Control as Limited Resource: Regulatory Depletion Patterns. Journal of Personality and Social Psychology, 74, 774-789. http://dx.doi.org/10.1037/0022-3514.74.3.774

Nichols, A. L., \& Cottrell, C. A. (2008). The Multiple Audience Problem: Considering Situational and Personality Factors. Proceedings of the 9th Annual Society for Personality and Social Psychology Conference, Albuquerque, 7-10 February 2008, 228.

Rosenfeld, P., Giacalone, R. A., \& Riordan, C. A. (2002). Impression Management: Building and Enhancing Reputations at Work. London: Thomson Learning.

Schlenker, B. R. (1975). Self-Presentation: Managing the Impression of Consistency When Reality Interferes with SelfEnhancement. Journal of Personality and Social Psychology, 32, 1030-1037. http://dx.doi.org/10.1037/0022-3514.32.6.1030

Schlenker, B. R. (1980). Impression Management: The Self-Concept, Social Identity, and Interpersonal Relations. Monterey, CA: Brooks/Cole.

Schlenker, B. R. (2003). Self-Presentation. In M. R. Leary, \& J. P. Tangney (Eds.), Handbook of Self and Identity (pp. 492-518). New York: Guilford.

Swann, W. B., Bosson, J. K., \& Pelham, B. W. (2002). Different Partners, Different Selves: Strategic Verification of Circumscribed Identities. Personality and Social Psychology Bulletin, 28, 1215-1228.

http://dx.doi.org/10.1177/01461672022812007

Tesser, A., \& Moore, J. (1986). On the Convergence of Public and Private Aspects of Self. In R. Baumeister (Ed.), Public Self and Private Self (pp. 99-116). New York: Springer-Verlag. http://dx.doi.org/10.1007/978-1-4613-9564-5_5

Tice, D. M., Butler, J. L., Muraven, M. B., \& Stillwell, A. M. (1995). When Modesty Prevails: Differential Favorability of Self-Presentation to Friends and Strangers. Journal of Personality and Social Psychology, 69, 1120-1138. http://dx.doi.org/10.1037//0022-3514.69.6.1120

Vallacher, R. R., \& Wegner, D. M. (1987). What Do People Think They're Doing? Action Identification and Human Behavior. Psychological Review, 94, 3-15. http://dx.doi.org/10.1037/0033-295x.94.1.3

Van Boven, L. V., Kruger, J., Savitsky, K., \& Gilovich, T. (2000). When Social Worlds Collide: Overconfidence in the Multiple Audience Problem. Personality and Social Psychology Bulletin, 26, 619-628. http://dx.doi.org/10.1177/0146167200267009

Vohs, K. D., \& Baumeister, R. F. (2004). Ego-Depletion, Self-Control, and Choice. In J. Greenberg, S. L. Koole, \& T. Pyszczynski (Eds.), Handbook of Experimental Existential Psychology (pp. 398-410). New York: Guilford Press.

Vohs, K. D., \& Heatherton, T. F. (2000). Self-Regulatory Failure: A Resource-Depletion Approach. Psychological Science, 11, 249-254. http://dx.doi.org/10.1111/1467-9280.00250

Vohs, K. D., \& Schmeichel, B. J. (2003). Self-Regulation and the Extended Now: Controlling the Self Alters the Subjective Experience of Time. Journal of Personality and Social Psychology, 85, 217-230. http://dx.doi.org/10.1037/0022-3514.85.2.217

Vohs, K. D., Baumeister, R. F., \& Ciarocco, N. (2005) Self-Regulation and Self-Presentation: Regulatory Resource Depletion Impairs Impression Management and Effortful Self-Presentation Depletes Regulatory Resources. Journal of Personality and Social Psychology, 88, 632-657. http://dx.doi.org/10.1037/0022-3514.88.4.632

Watson, D., Clark, L. A., \& Tellegen, A. (1988). Development and Validation of Brief Measures of Positive and Negative Affect: The PANAS Scales. Journal of Personality and Social Psychology, 54, 1063-1070. http://dx.doi.org/10.1037/0022-3514.54.6.1063 